\title{
Avis + Elsmere: A Collaborative Community Design Precedent
}

\section{CEARA O'LEARY, Senior Designer and Project Director}

University of Detroit Mercy \&

Detroit Collaborative Design Center
TADD HEIDGERKEN, Assistant Professor, Architect

University of Detroit Mercy \&

Et al. Collaborative

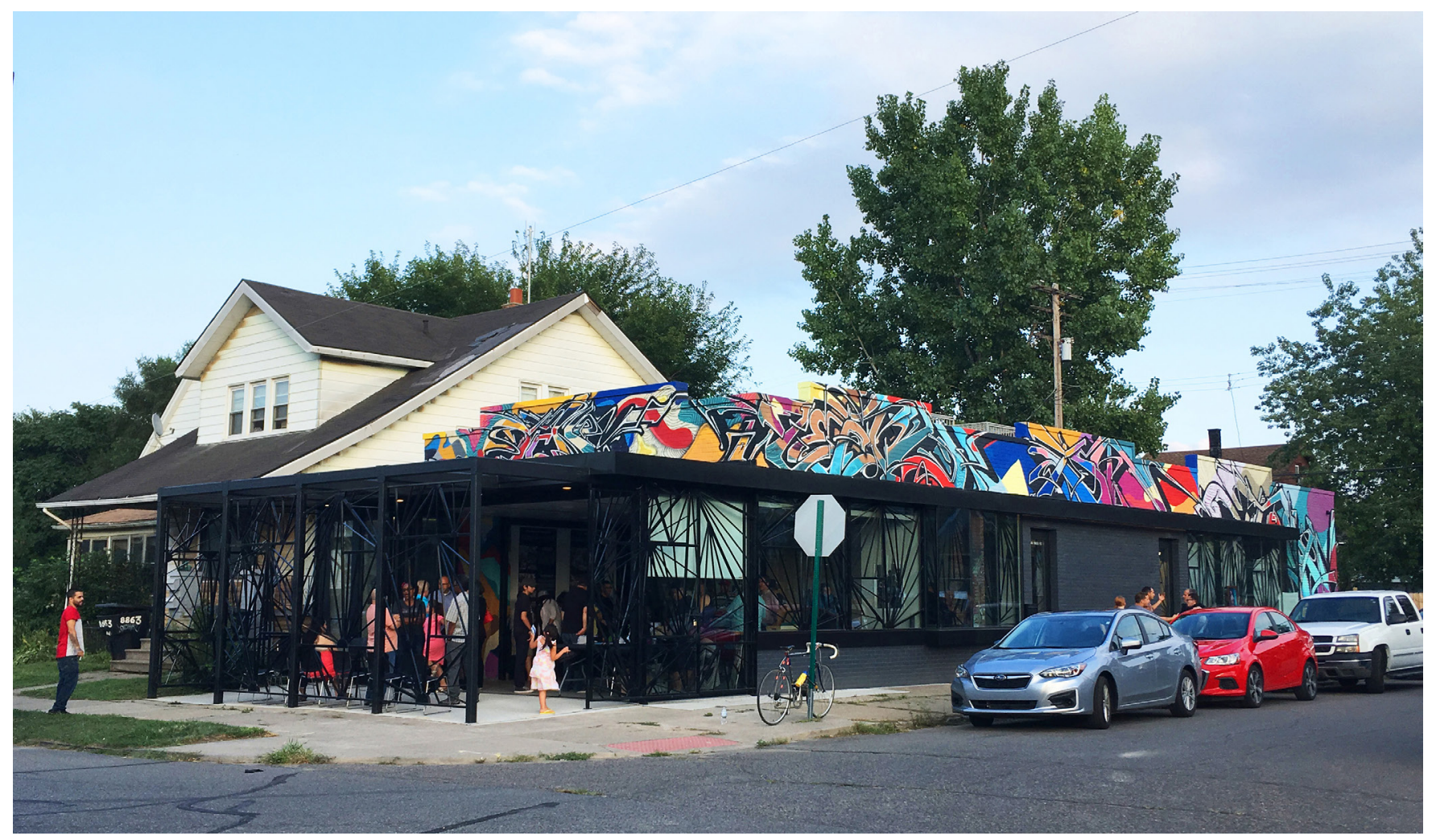

Figure 1. Community activating the front porch of the Avis + Elsmere building following the completion of the construction phase. (Credit: Erik Howard)

\section{INTRODUCTION}

Vibrant neighborhood spaces pave the way for more resilient and inclusive communities. This paper showcases a neighborhood space resulting from a collaborative, community-led design process that honors local knowledge and responds to contextual challenges. Avis + Elsmere, a project in Detroit, offers a model for collaborative practice as the product of a robust relationship between the client-collaborator - grassroots organization Inside Southwest Detroit - a diverse stakeholder group of neighbors and artists, the Detroit Collaborative Design Center (DCDC) at the University of Detroit Mercy (UDM), and the architecture office Et al. Collaborative.

Inside Southwest Detroit is a collection of initiatives that promote youth and community development through cultural and place-based initiatives. One of their flagship initiatives completed in 2011, "The Alley Project," transformed a Southwest Detroit neighborhood alley and surrounding vacant lots into an inspirational graffiti art gallery, which connects neighbors and youth to each other as well as to community assets. Avis + Elsmere provides an anchor to The Alley Project through the renovation of an existing 2,400 square-foot building into a community center, Inside Southwest Detroit headquarters, and leasable tenant area. Avis + Elsmere is the first year-round home to Inside Southwest Detroit programs and reflects community vision in its planning, execution and everyday use.

An organization that aims to build meaningful relationships between neighborhood youth and elders using low-rider car club and street art cultures, Inside Southwest Detroit needed 


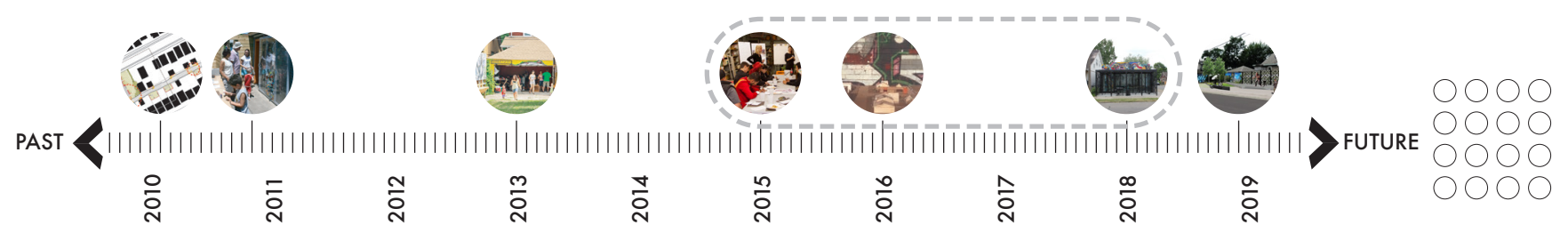

Figure 2. The timeline shows different connection points between Young Nation, the University of Detroit Mercy, Detroit Collaborative Design Center and Et al. Collaborative. The collaborative effort began with the DCDC's assistance in development a master plan for the neighborhood in 2010 with the latest being the completion of the new community building in 2018. A new Skate Plaza is schedule to begin construction Fall 2019 on an adjacent lot. (Credit: Authors)

a space that would support and enhance their mission to bring the neighborhood together. The project began with a participatory process that engaged key stakeholders - graffiti artists, skateboarders, kids, grandparents, and other neighbors - in project planning and design decision making, resulting in a community space that responds to local culture, needs and opportunities. A series of community workshops, focus groups and neighborhood celebrations gave people the agency and opportunity to guide the design of the building. The spaces and materials resulted directly from the collaborative design process and speak to the neighborhood's identity and vibrancy.

Avis + Elsmere is part of a larger trajectory of initiatives led by Inside Southwest Detroit that have resulted from a collaboration with a range of partners, including design and architecture practices. This project offers lessons for how long-term collaboration over time leads to layered projects with neighborhood roots and a common design conversation. Because of the robust community workshop process and shared participatory values of the community partner and designers, it also illustrates how engagement processes can maximize design decision making that merges community knowledge and architectural expertise. In turn, it offers a model for practice beyond community design centers, including the incorporation of participatory process in the design practice of small firms working at the neighborhood scale.

\section{COLLABORATORS + COLLABORATION}

Avis + Elsmere bookends The Alley Project (TAP), an Inside Southwest Detroit initiative and community-based public art space on the southwest side of Detroit. Its mission is to provide a space to facilitate the themes of creative expression, positive youth-adult partnerships, structure, and community responsibility. TAP includes a garage converted to host a studio and gallery space, two lots serving as a common art space, and an alley spanning one city block with murals installed on garage doors. In these spaces youth and community members can create, show, and/or see street art in a way that is legal, safe, and supports learning and relationships. These spaces were envisioned, designed and implemented in partnership with the UDM School of Architecture and the DCDC as they guided TAP's master planning and participatory design and build during the formation of The Alley Project.
DCDC is a multi-disciplinary, nonprofit architecture and urban design firm based at the UDM School of Architecture dedicated to creating sustainable spaces and communities through quality design and the collaborative process. DCDC focuses on participatory design processes that value community expertise and prioritize local knowledge as a design driver. These processes are also central to Inside Southwest Detroit's operations, which has contributed to a strong partnership. This partnership developed into a long-term relationship and a series of collaborative projects between Inside Southwest Detroit and DCDC, folding in a range of instrumental partners, ranging from neighbors and artists to architects and fabricators. The 2010 master plan connects several neighborhood organizations via an extension of TAP into the larger network of area alleyways and continues to guide growth, including the design and implementation of Avis + Elsmere.

Another key collaborator in the development of Avis + Elsmere is Et al. Collaborative, a small architecture firm based in Detroit, with principals on faculty at both UDM and Lawrence Technological University. Et al. Collaborative was invited to participate on the project as a result of relationships built at the University of Detroit Mercy. From the outset, Inside Southwest Detroit, DCDC and Et al. identified the importance of all partners and community stakeholders being involved throughout the design process. Because DCDC focuses on community-engaged design, they led the participatory workshop process resulting in schematic design, while Et al. led subsequent design development and documentation. Both firms participated throughout, with Et al. attending and advising throughout schematic design in a shared authorship role with community members, Inside Southwest Detroit, and DCDC. DCDC staff followed the project through construction drawings and documentation. This team intention ensured consistent community presence and a more robust collaborative structure resulting in a stronger product and community space.

Notably, Avis + Elsmere is one project in a series of initiatives in the neighborhood that have developed from an evolving set of collaborators. While Inside Southwest Detroit and DCDC early collaborated on The Alley Project and various design build student projects, Et al. Collaborative and DCDC have 


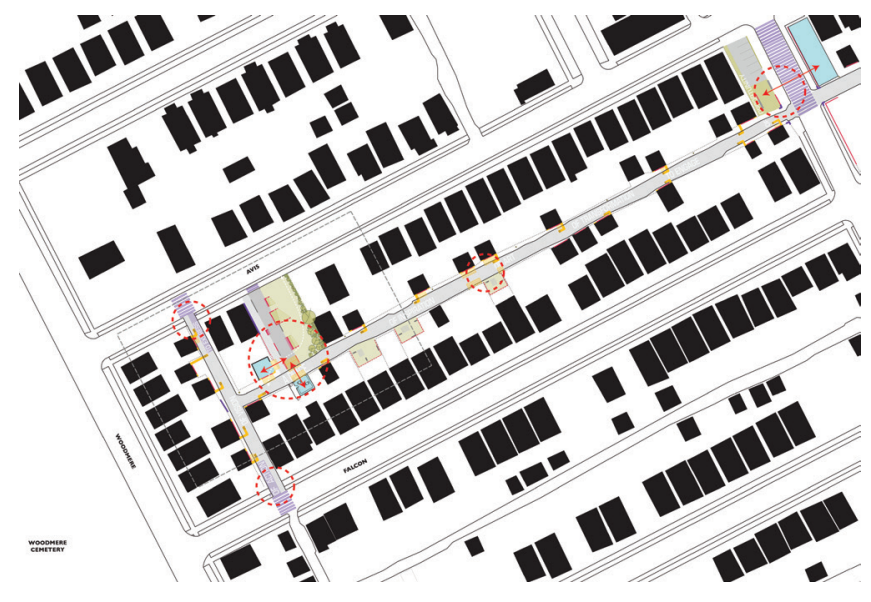

Figure 3. The master plan of the neighborhood surrounding TAP was created along with the local community and stakeholders. The framework planning process led to the implementation of a series of temporary activations and installations as well as the identifying a roadmap for new opportunities to grow; including identifying a need for a long term building that would support the community members needs. (Credit: DCDC)

continued their partnership in collaboration with another neighborhood nonprofit, Grace In Action, in the design of a plaza that will mark a physical and programmatic extension of and complement to The Alley Project. This ongoing collaborative practice between university-based community design center and small for-profit architecture firm also continues to evolve. The relationship has resulted in a cross-pollination of engagement lessons, design development, staff time, and lessons that can be applied both in the office, the community and the classroom, as all faculty designers have teaching practices.

\section{DESIGN PROCESS}

The Alley Project is a sort of social micro-community made up of four distinct groups of stakeholders: Youth, Neighbors, Artists, and Organizations. This community comprised the stakeholder group that defined the program and design of Avis + Elsmere. The audience and participants for Avis + Elsmere are the surrounding community, particularly young neighbors and creative residents. This community is comprised of painters, graffiti artists, grandparents, skateboarders, musicians, photographers, advocates, and more. These are also the stakeholders who led design decision making, resulting in a community space that accommodates a range of activities that respond to local needs.

The participatory design process for Avis + Elsmere grew from local culture and generated the building design, from program and site to materials and details. Engagement activities included neighborhood-wide outreach, including door-todoor postcards that invited program ideas and visits to the site as well as a celebratory design review event. The focus of the participatory process, however, was a series of community stakeholder workshops through which the program

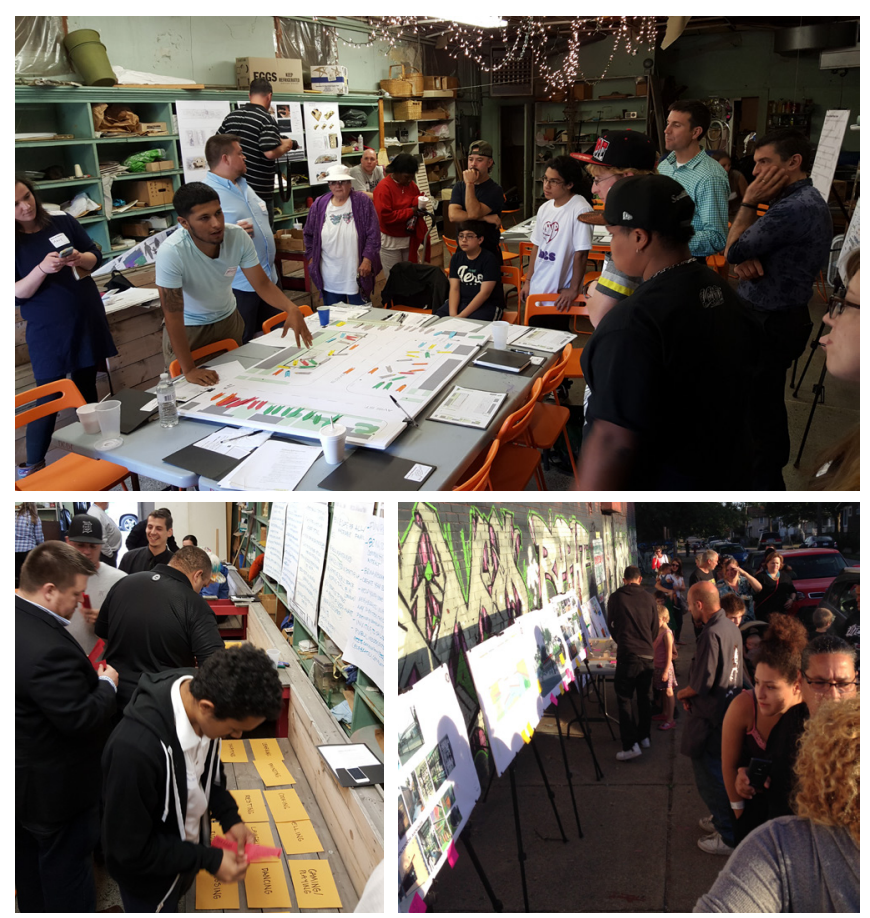

Figure 4. Engagement workshops and celebrations are not only tools for strengthening the bonds of the neighbors but they provide venues for voices to be heard and for sympathetic people to listen. The workshops have been used throughout each phase and are also used as a living feedback loop for the institution along with their consultants. (Credit: Erik Howard)

and design for the building and adjacent plaza were developed. Together, DCDC and Inside Southwest Detroit identified a representative group of key stakeholders to lead design decision making, including skaters, painters, kids, elders, and neighbors. A series of three workshops with this group led to the final design.

An initial activity set design intentions through a visioning exercise asking "If this project does nothing else, it should..." Collective brainstorming of action verbs generated initial program ideas. These program verbs were prioritized with participants expressing their values with "TAP cash" -- with "revolutionizing" emerging as the top verb to design toward. In a subsequent workshop, community stakeholders identified key program relationships with site plans, tags, string, and transparent sheets, resulting in key adjacencies, space priorities, and more key programmatic insights which are detailed below. Material and space design considerations were also explored and defined in these workshops. In addition to the workshops, a series of additional focus groups were held with program experts to flesh out design needs, including street artists, skateboarders, and potential neighborhood business tenants.

The design challenge was to create a flexible, accessible, and authentic space which reflected the values of the community. 
The north facade was removed to create a larger community room, which opens onto an enclosed 'front porch' area. The porch is enclosed by the geometric-patterned ornamental ironwork screens, which reference fences and screens prevalent in the neighborhood, contributing to both security and transparency. Local metalworkers fabricated the screens. The mural which wraps throughout the building was designed by a late street artist and completed in tribute by an Inside Southwest Detroit program alumnus. This artwork brings the activity of the adjacent The Alley Project to the front of the building and the main corners of the neighborhood. Large windows pop from the west facade for a visual connection to the street and future adjacent plaza. On the interior, wood finish panels in bold colors and subtle patterns reference the mural and metalwork, and large moveable doors allow flexibility of spaces as well as provide functional writeable surfaces for meeting notes and impromptu artwork.

The program and screened front porch are key design elements that illustrate the direct role of community members in design development. During the workshop series mentioned above, two groups developed program layout diagrams which resulted in a key conversation about the site layout -- should the flexible community space be sited along the alley, as a continuation of The Alley Project, or at the street corner, for greater visibility. Ultimately the corner site was identified for access, visibility and street presence, the direct result of community conversations. Similarly, these conversations resulted in the service core with restrooms and kitchen areas that can be accessed from the outdoors, the tenant space or the community space independently. Relationships between the building and forthcoming plaza were also identified. In these conversations, lessons from past projects were folded into the design making process.

The most striking design element of the building -- the screened front porch -- was similarly workshopped and developed through community conversations. One of the key considerations discussed during the workshop series was a need to balance security concerns with a feeling of openness and accessibility. The screen seeks to create this balance through an artistic means, fabricated by a local metal shop and speaking to the ironwork that is prevalent in the neighborhood. The screen design was finessed through a series of additional community conversations. The front porch achieves an indooroutdoor space that invites the community to participate and connects to the street, to neighbors, and to the future plaza.

\section{MODEL FOR PRACTICE + LESSONS FOR FUTURE COLLABORATIONS}

In terms of working with community partners, the value of time and the evolution of collaboration cannot be overstated. The engagement loop built into the design process early on propelled the design process, resulted in a project that reflects community vision, and led to additional projects

\section{ET AL. + DCDC COLLABORATION}
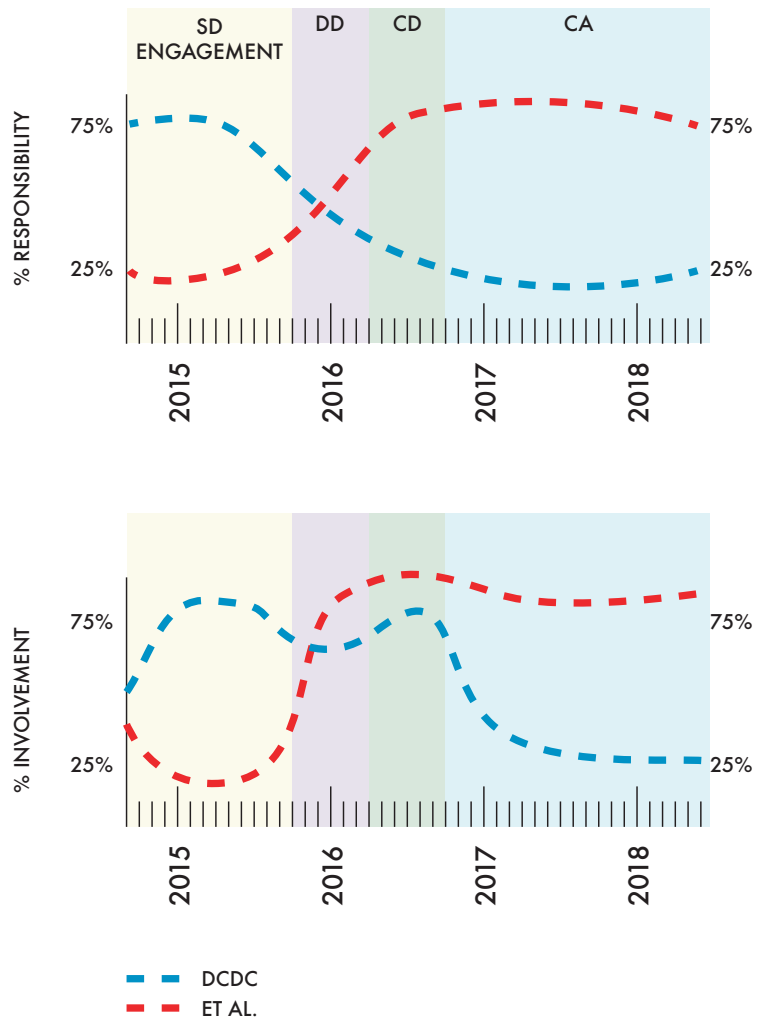

Figure 5. Diagrams communicating the differing roles and responsibilities both the DCDC and Et al. Collaborative had during the duration of the design and construction of 8869 Avis. (Credit: Authors)
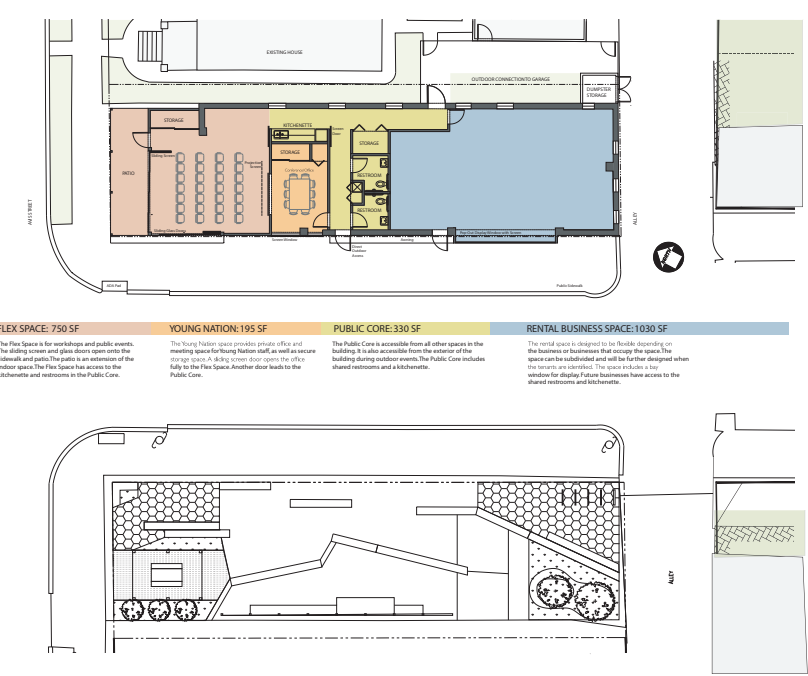

Figure 6. Avis + Elsmere floor plan along with the skate plaza site plan that is scheduled to begin construction in the Fall 2019. (Credit: Authors) 

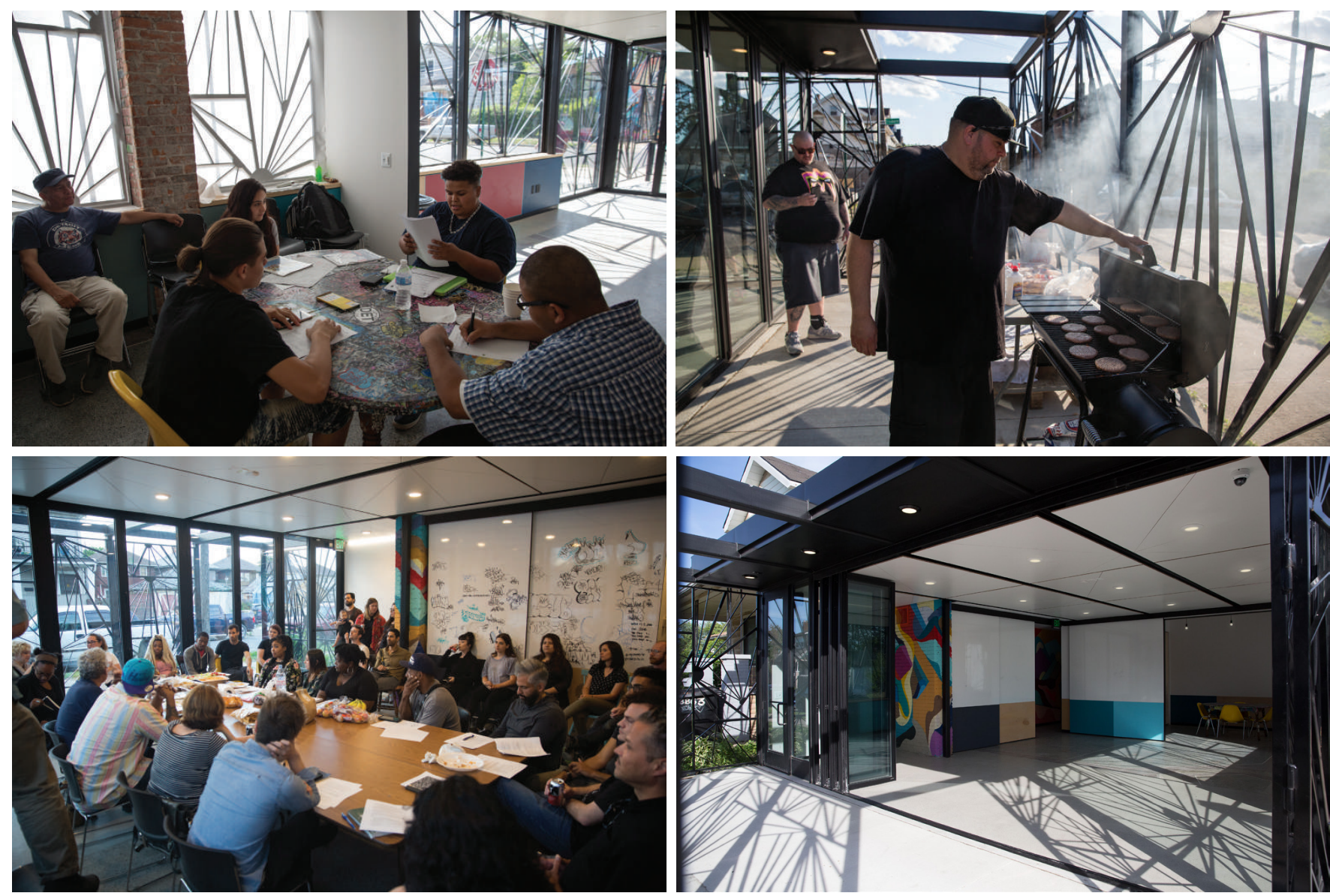

Figure 7. Avis + Elsmere and the flexible spaces provided a needed facility for both the local and visiting communities to gather together. (Credit: Erik Howard)

and collaborations throughout the neighborhood. The design process itself led to deeper networks within the community that contributed to long-term trust-building between project partners and subsequent projects generated from the knowledge and relationships built within the community over time.

This project also offers lessons for both community-engaged design processes and small architecture practices participating in these processes. In traditional practice, architecture offices are tasked with balancing budget, timeline and project quality. This equation does not change when folding in community-engaged design processes, but the time necessary for a meaningful participatory process must be valued and acknowledged by all partners and built into the project framework and pricing. Often with community processes the oft-iterative design process becomes still more iterative and includes a diverse range of voices, which must be considered and valued from the outset.

Part of this project framework involves setting parameters from the outset, while maintaining an open mind to the project evolution that may result through sincere engagement. Project constraints should be established with the partner as well as community stakeholders. Budget, timeline, scope and effort need to be articulated, along with their value from the outset, based on the needs and resources of the client-collaborator. On the community front, DCDC-led engagement processes often begin with a review of project "givens" or non-negotiables. In the case of Avis + Elsmere, these project givens included, but were not limited to: the project must follow all relevant codes; the project must include a 1000sf leasable tenant space in order to generate income and be self sufficient; the project must be welcoming to all and include all voices. Community stakeholders also had an opportunity to add project givens at the first workshop.

Time is a recurring theme within community design at large as well as the series of collaborative projects between Inside Southwest Detroit, DCDC, and Et al. Tactically, time constraints are important parameters for a project. Community-engaged projects require a realistic schedule based on the needs of the client-collaborator that depart from traditional architecture practice, and require a slower pace to allow for stakeholder engagement and meaningful incorporation of community input into the design process, including time for unforeseen iterations. Ample time for a two-way exchange of information and clear benchmarks for community participation must be 


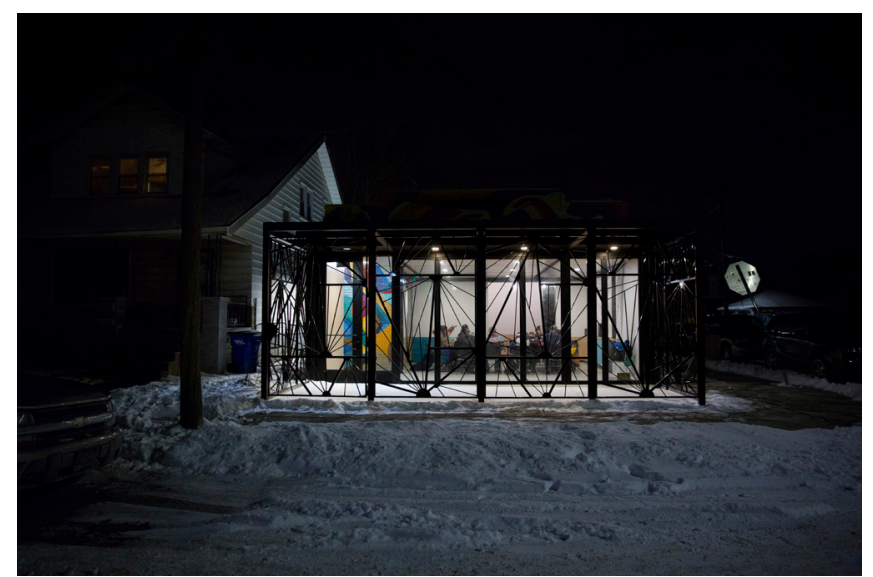

Figure 8. Visibility was a tool identified by the community members during the design workshops as a way to enhance both community connections and security. (Credit: Erik Howard)

built into the design schedule and process. Like other projects, timelines for community-engaged projects also evolve based on budget and unforeseen opportunities and constraints. In the case of Avis + Elsmere, the forthcoming plaza across the street from the building was initially anticipated as part of the first construction phase but due to a focus on meeting key goals for the building design, the plaza was ultimately shifted to a later funding and implementation phase. This flexibility and change over time speaks to the creative problem solving and agility with which collaborative teams must navigate projects and leverage opportunities. It also speaks to the need to support neighborhood nonprofits and adapt the design process as they seek funding for built projects.

Finally, Avis + Elsmere is one in a series of projects that mark an ongoing collaboration between DCDC and a UDM faculty practice, offering lessons for future projects working in tandem. One key family of lessons pertains to the need for a constant incorporation of community voices into the design process. As described above, DCDC and Et al. were involved throughout the design process, with varying levels of engagement, in order to ensure that the full design team, including community stakeholders, was present and listening throughout the design process. This frequency of communication is not easily achieved, given time and budget constraints but the consistency of staffing allows a more steady feedback loop. In the case of Avis + Elsmere, DCDC staff worked with Inside Southwest Detroit to act as conduits for continued community feedback throughout design development post-community workshops. This enabled check ins during construction documentation to ensure ongoing alignment with community project goals, which in one case led to an additional focus group as the screen design was under development. This feedback process needs to be baked in to expectations and project workflow, as does a clear understanding of roles for all partners, so time can be fully anticipated and allocated.
In this collaborative model of practice, a defined balance between staff roles and relationships that benefits both the university-based design center and faculty practice is key. In particular, the balance of fees and staff time with two firms working in parallel to ensure continuity throughout the design process and meet the project budget with a nonprofit partner is challenging. This team did not always strike all the right balance throughout the Avis + Elsmere design and development process, but the benefit of a long-term collaborative partnership between university-based community design center, faculty-led architecture office and neighborhood nonprofit organization is the opportunity to improve upon our processes and strengthen our relationships moving forward, building upon lessons learned.

This project showcases a robust collaborative process and participatory design effort, the results of which were shaped by neighbors and users - from skaters to painters - and offers a model for future design development with community that builds from past projects as well. From the program and neighborhood connections to the façade and division of spaces, the project was driven by resident voices and brought to life with designer-collaborators. Here, process sets an example for creating inclusive and responsive places that serve community and create safe spaces for revolutionizing. 